
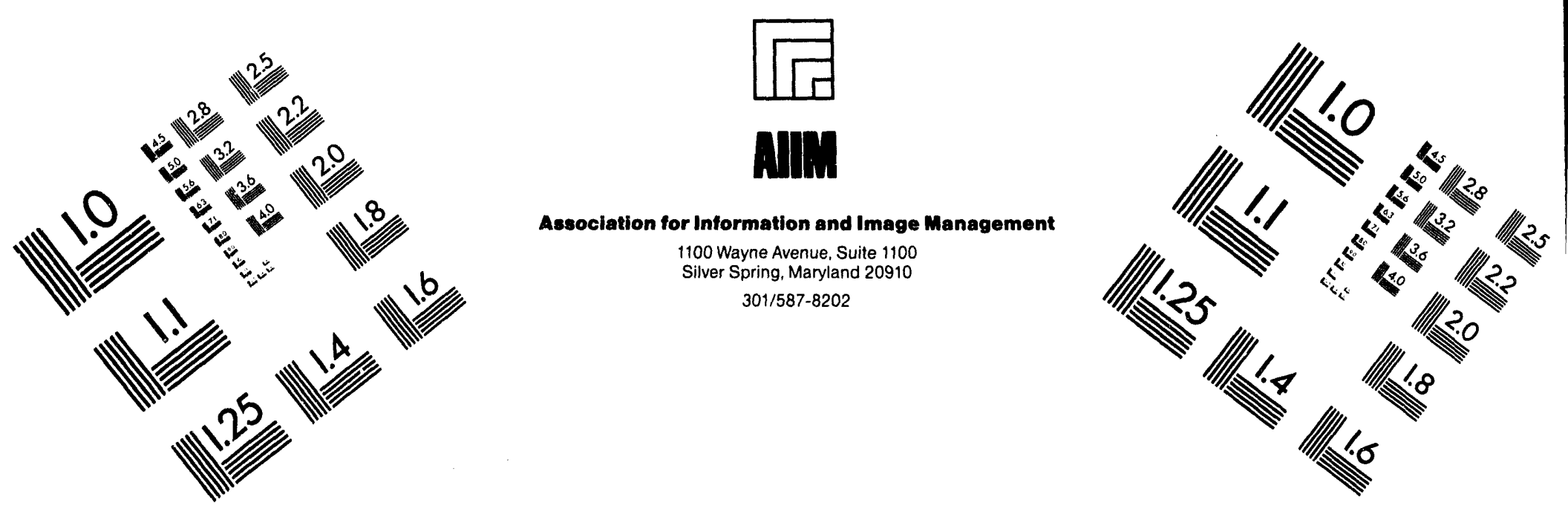

Centimeter

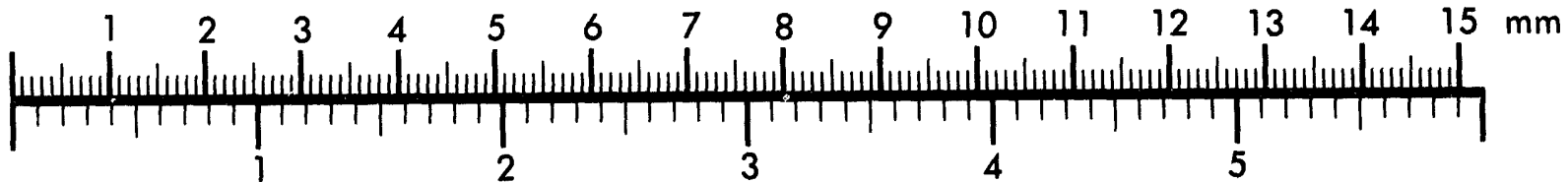
Inches
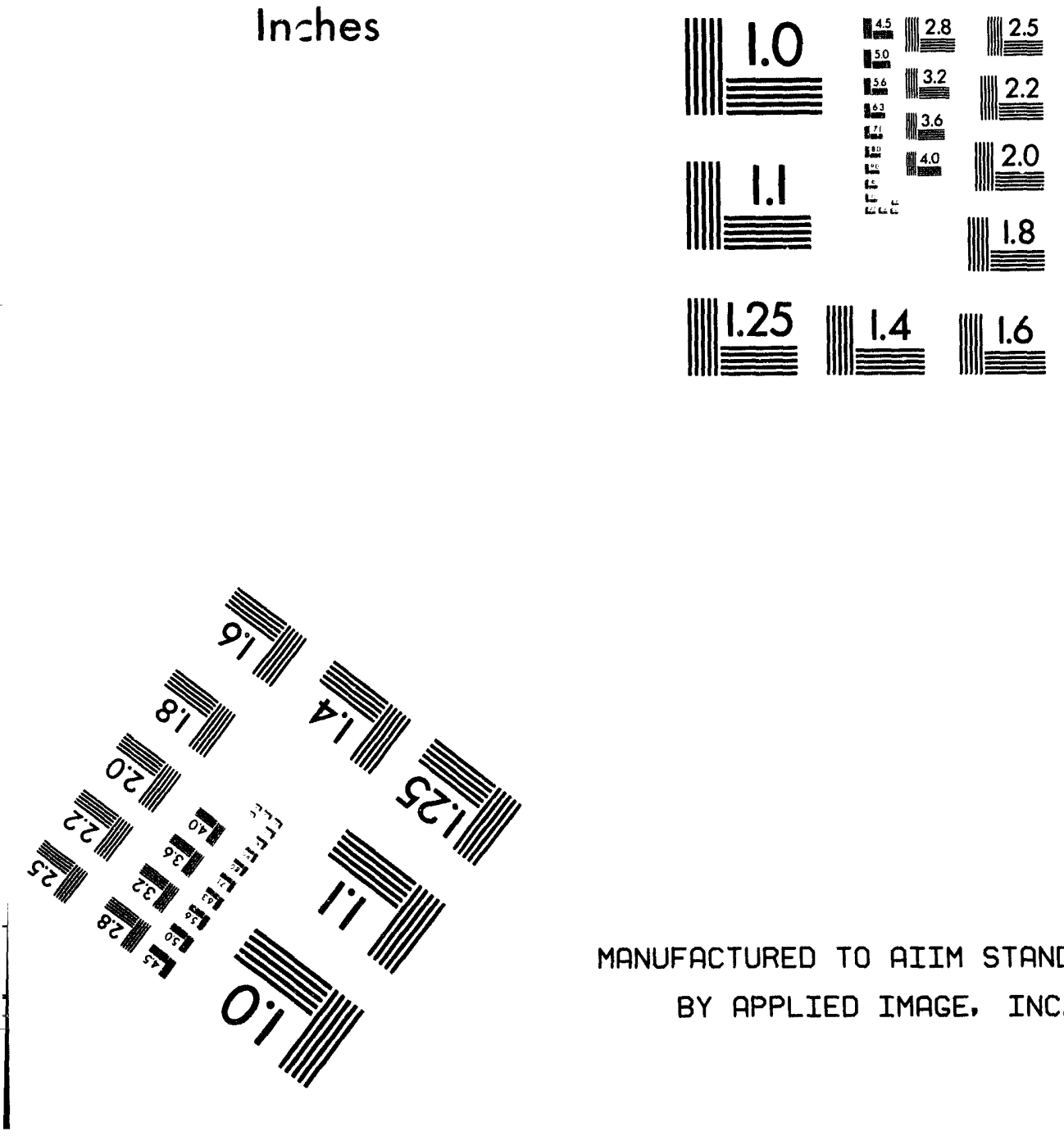

MANUFACTURED TO AIIM STANDARDS

BY APPLIED IMAGE, INC.

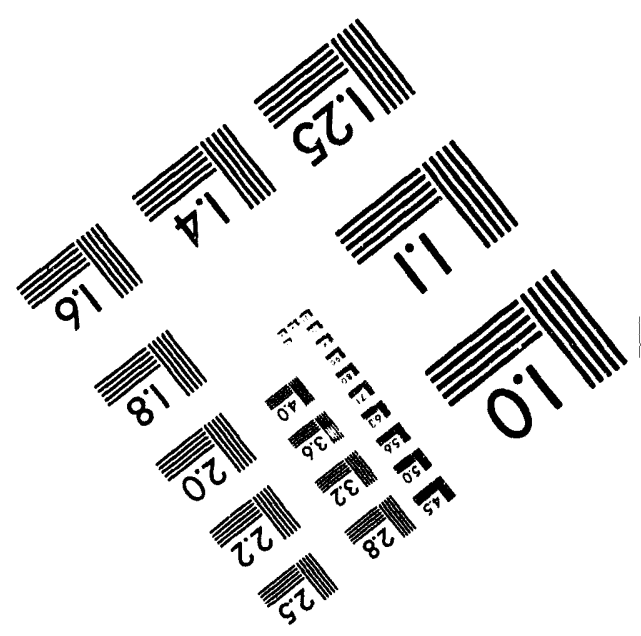



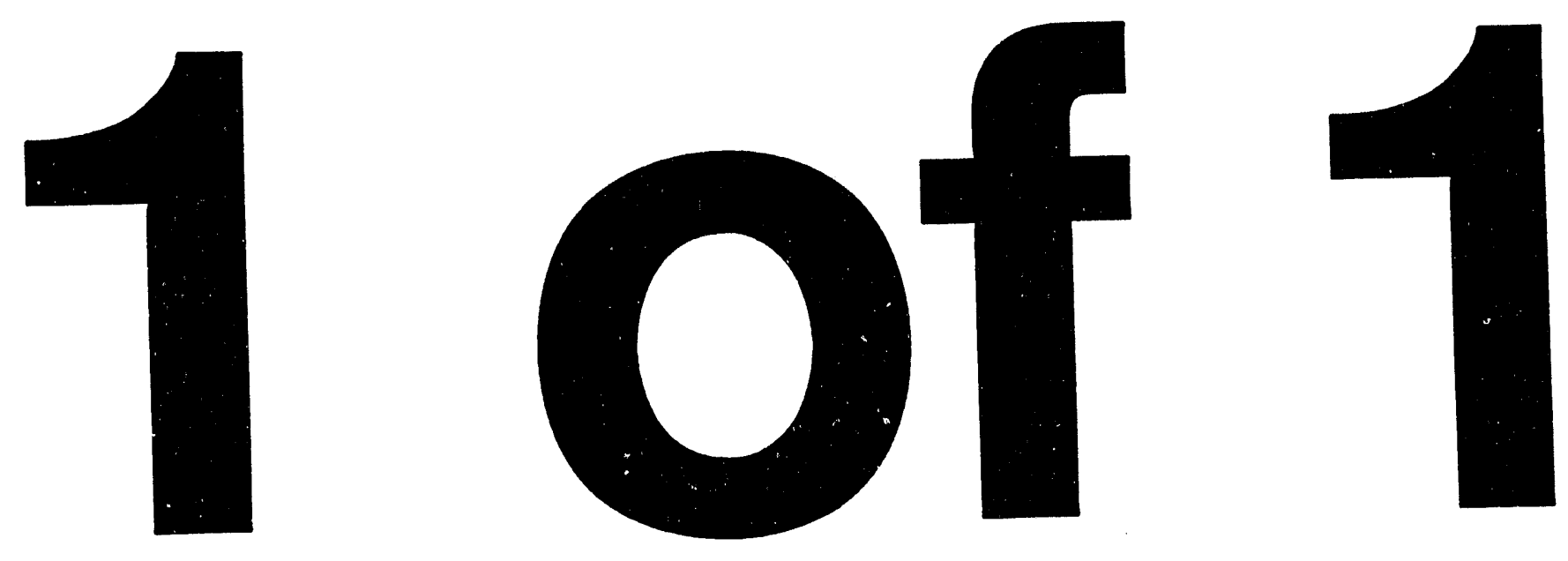
UCRL-JC- 116339

PREPRINT

\title{
Ductile-Brittle Transition Behavior of Tingsten Under Shock Loading
}

\author{
David H. Lassila, G. T. Gray III
}

This paper was prepared for submittal to the DYMAT '94 International Conference on Mechanical and Physical Behavior of Materials Under Dynamic Loading, Oxford U.K., Sept. 26-30, 1994

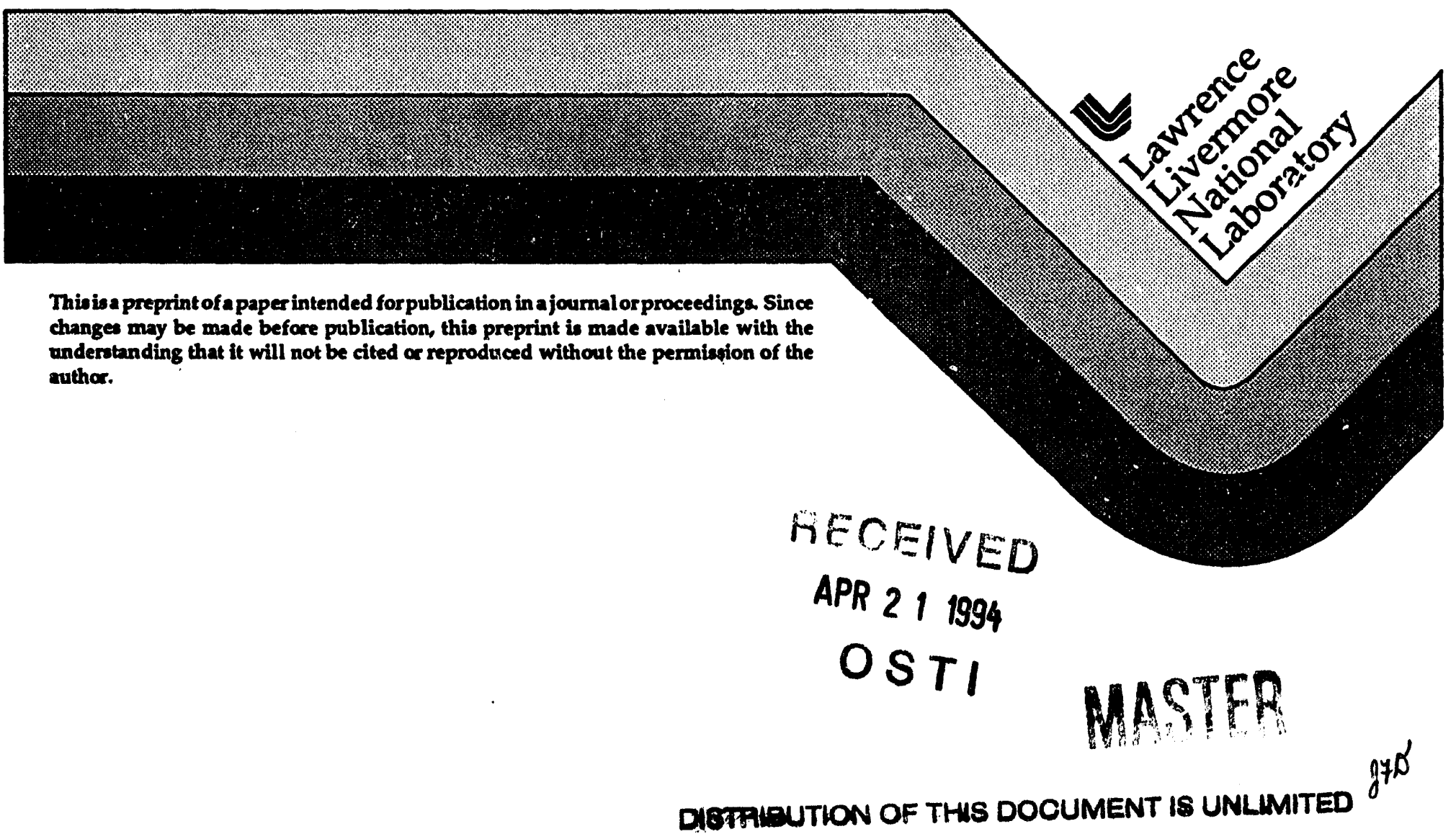




\section{DISCLAIMER}

This document was prepared as an account of work sponsored by an agency of the United States Government. Neither the United Stutes Government nor the University of California nor any of their employees, makes any warranty, express or implied, or assumes any legal liability or responsibility for the accuracy, completeness, or usefulness of any information, apparat us, product, or process disclosed, or represents that its use would not infringe privately owned rights. Reference herein to any specificcommercial products, process, or service by trade name, trademark, manufacturer, or otherwise, does not necessarily constitute or imply its endorsement, recommendation, or favoring by the United States Government or the University of California. The views and opinions of authors expressed herein do not necessarily state or reflect those of the United States Government or the University of California, and shall not be used for advertising or product endorsement purposes. 


\title{
DUCTILE-BRITTLE TRANSITION BEHAVIOR OF TUNGSTEN UNDER SHOCK LOADING
}

\author{
D. H. Lassila \\ University of California \\ Lawrence Livermore National Laboratory \\ Livermore, CA 94550 USA \\ G. T. Gray III \\ University of California \\ Los Alamos National Laboratory \\ Los Alamos, NM 87545 USA
}

\begin{abstract}
The ductile-brittle transition behavior of warm-forged tungsten under shock loading conditions was examined by performing shock/soft-recovery experiments at $22^{\circ}$ $\mathrm{C}$ and $400^{\circ} \mathrm{C}$. The results of a recovery experiment at $22^{\circ} \mathrm{C}$ indicate that shock $(19 \mathrm{GPa})$-induced strains were accommodated by fracture processes, i.e. there were no indications of shock-induced plastic deformation, and the tesc sample was reduced to rubble. At $400^{\circ} \mathrm{C}$ the test sample was recovered intact and the shock-induced plasticity caused deformation banding and an increase in the dislocation density of the material. The results of these experiments demonstrate the principle of a ductile-brittle transition behavior of tungsten under uniaxial shock loading conditions and indicate that explosively-driven deformation of the material studied will likely result in pulverization due to shock loading.
\end{abstract}

\section{INTRODUCTION}

The mechanical behavior of tungsten, like many body center cubic (BCC) metals, is characterized by a ductile-britt'e transition temperature (DBTT) below which little or no macroscopic plastic deformation occurs prior to fracture $(1,2)$. The DBTT of tungsten has been studied extensively and has been found to be highly dependent on the nature of the material. For example, alloying additions $(3,4)$, interstitial impurities $(4,5)$, grain size with accompanying changes in impurity segregation $(6,7)$, and thermomechanical processing $(8,9)$ have all been reported to have profound effects on the DBTT. The DBTT has also been found to be dependent on the rate of loading $(10,11)$. In general, the ductile-brittle transition behavior occurs at higher temperatures with increasing strain rate.

Shock loading, via planar flier plate impact, subjects solids to unique strain, pressure and temperature histories (12). This deformation history is characterized by compressive uniaxial strain and high hydrostatic confining pressure. In this work we present results of two shock/soft- 
recovery experiments performed at temperatures of $22^{\circ} \mathrm{C}$ and $400^{\circ} \mathrm{C}$. Analysis of the results indicates that, as in the case of other types of mechanical loading, there is a DBTT associated with shock loading.

Table 1. Shock recovery experiments and results.

\begin{tabular}{|c|c|c|c|c|}
\hline Temperature & $\begin{array}{c}\text { Peak shock } \\
\text { pressure }\end{array}$ & $\begin{array}{c}\text { Shock } \\
\text { duration }\end{array}$ & $\begin{array}{c}\text { Transiont } \\
\text { train }\end{array}$ & Resulk \\
\hline $220 \mathrm{C}$ & $19 \mathrm{GPa}$ & $1 \mu \mathrm{s}$ & $7.2 \%$ & $\begin{array}{c}\text { Sample was } \\
\text { rubblized }\end{array}$ \\
\hline $400 \mathrm{C}$ & $15 \mathrm{GPa}$ & $1 \mu \mathrm{s}$ & $5.8 \%$ & $\begin{array}{c}\text { Sample } \\
\text { recovered } \\
\text { intact }\end{array}$ \\
\hline
\end{tabular}

\section{SHOCK/SOFT-RECOVERY EXPERIMENTS}

The test material was prepared by warm forging of a pressed and sintered powder metallurgy billet. Forging was performed at a temperature below the recrystallization temperature. Optical light metallography indicated an elongated grain structure and the average grain size was estimated to be about $30 \mu \mathrm{m}$. Bulk chemical analyses were performed and the levels of impurities were found to be as follows (by weight \%): $O=0.002, \mathrm{C}=0.002, \mathrm{~N}<0.001$, $\mathrm{C}<0.002$, all others less than 0.02 .

Shock-recovery experiments were performed using an 80-mm single stage gas gun (12). The specimen assembly, as shown in Figure 1, consisted of a 5.08-mm-thick, 38-mm-diameter sample, sandwiched behind a 38-mm-diameter, 2.54-mm-thick cover plate. Both components were tightly fitted into a bored recess of a $7^{\circ}$ - tapered, 12.7 -mm-thick, central momentum disk. The sample was protected from spallation by backing the central momentum disk with a 3.8-mm-thick spall plate. The central disk and spall plate were further surrounded by two concentric momentum trapping rings with outside diameters of $69.8 \mathrm{~mm}$ and $82.5 \mathrm{~mm}$.

Two assemblies were shock loaded in vacuum, one at a temperature of $22^{\circ} \mathrm{C}$ and the other at a temperature of $400^{\circ} \mathrm{C}$ (summaries of these experiments are given in Table 1). An insulated nichrome heating wire wrapped around the circunference of the shock assernbly was used to heat the shock assembly. Peak shock pressures of $19 \mathrm{GPa}\left(22^{\circ} \mathrm{C}\right.$ experiment) and $15 \mathrm{GPa}$ $\left(400^{\circ} \mathrm{C}\right.$ experiment) were achieved by impacting the specimen assembly with a tungsten flyer plate at velocities of $459 \mathrm{~m} / \mathrm{s}$ and $367 \mathrm{~m} / \mathrm{s}$ respectively. The thickness of the flyer plate $(2.2 \mathrm{~mm})$ resulted in shock durations of $1 \mu \mathrm{s}$. Soft recovery and simultaneous cooling are achieved by decelerating the central momentum disk in a water catch chamber positioned immediately behind the impact area.

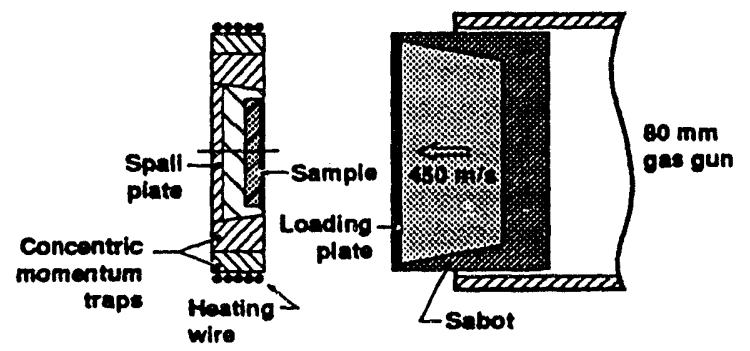

Figure 1. Sectional view of sample assembly and sabot/flyer-plate.

The shock/soft-recovery assembly (and sample) shock loaded at $22^{\circ} \mathrm{C}$ were reduced to rubble. The caich tank was searched for remnants of the sample (which were identified by the thickness of the recovered pieces) and approximately $20 \%$ of the rubblized sample was recovered. Most of the recovered pieces measured on the order of $3 \mathrm{~mm}$ by $3 \mathrm{~mm}$. The experiment performed at $400^{\circ} \mathrm{C}$ resulted in the recovery of the sample intact. The final thickness of this intact shocked disk was measured and the residial strain was calculated to be approximately $1 \%$. In addition to the residual strain through the thickness, the shock recovered disk was found to be slightly dished (approximately $1 \mathrm{~mm}$ out of flat at the center).

\section{MICROSTRUCTURAL ANALYSES}

\subsection{Optical light metallography}

Metallographic examination of the shocked material indicated that shock loading at $22^{\circ} \mathrm{C}$ resulted in massive amounts of internal cracking (in addition to the obvious particulation) as shown in Figure 2-a. The internal cracking appeared to occur predominately along the vestiges of grain boundaries that were initially formed in the powder billets during sintering. The microstructure of the material shock loaded at $400^{\circ} \mathrm{C}$ was found to have no internal cracking and significant amounts of deformation banding, as shown in Figure 2-b. The deformation banding could be due to extensive slip and/or deformation twins, although no evidence of deformation twinning was found using 
transmission electron microscopy (TEM). There were no indications of banding of this nature observed in the material shocked at $22^{\circ} \mathrm{C}$, which suggests that the shock-induced deformation which occurred at this temperature was accommodated primarily by internal cracking (in addition to elastic deformation).

\subsection{Transmission Electron Microscopy}

The substructures of the tungsten in the starting condition and following shock pre-straining at $22^{\circ} \mathrm{C}$ and $400^{\circ} \mathrm{C}$ were examined using TEM. The tungsten was sectioned parallel to the loading direction using a low-speed diamond saw and the slices were mechanically thinned resulting in $100-\mu \mathrm{m}$-thick foils. The foils were mechanically dimpled using 3-micron-diamond paste to a center thickness of nominally 25 microns. TEM foils were ion-milled at approximately $-150^{\circ} \mathrm{C}$ using a $6 \mathrm{kV}$ ion source at a grazing angle of 10 to 15 degrees. Characterization of the test materials was performed using a JEOL 2000EX equipped with a double-tilt: stage at an accelerating voltage of $200 \mathrm{kV}$.

The substructure of the tungsten following the shock/soft-recovery at $22^{\circ} \mathrm{C}$ exhibited a low overall dislocation density, similar to the starting material. This substructure suggests that the strains induced during the shock prestraining at $22^{\circ} \mathrm{C}$ were, by and large, not accommodated by generation and movement of dislocations (plastic deformation). Such a response would be similar to a truly brittle material which has insufficient slip systems to accommodate the deformation imposed by the shock process, e.g. a ceramic material.

The substructure of the starting material, shown in Figure 3-a, consists of subgrains with low angle boundaries (nominally 3 microns in diameter) containing a relatively low density of dislocations. The dislocations observed were found to be long-straight screw type dislocations. This observation is consistent with the substructures previously seen in a number of refractory metals. Due to the disparity in the forces needed to move and cross-slip screw vs. edge dislocations, edge dislocations can more readily accumulate or annihilate into the subgrain walls. The screw segments are more difficult to move because of the kinking process necessary for them to propagate.

The substructure of the tungsten after shock prestraining at $400^{\circ} \mathrm{C}$ has a significantly higher dislocation density in the subgrain interiors, as shown in Figure 3-b. The substructure within the subgrains consists of random dislocation tangles in most subgrains and some reorganization of these tangles into dislocation cells in some of the larger subgrains. Reduction in the local strain energy will drive this reorganization to form a cellular configuration.

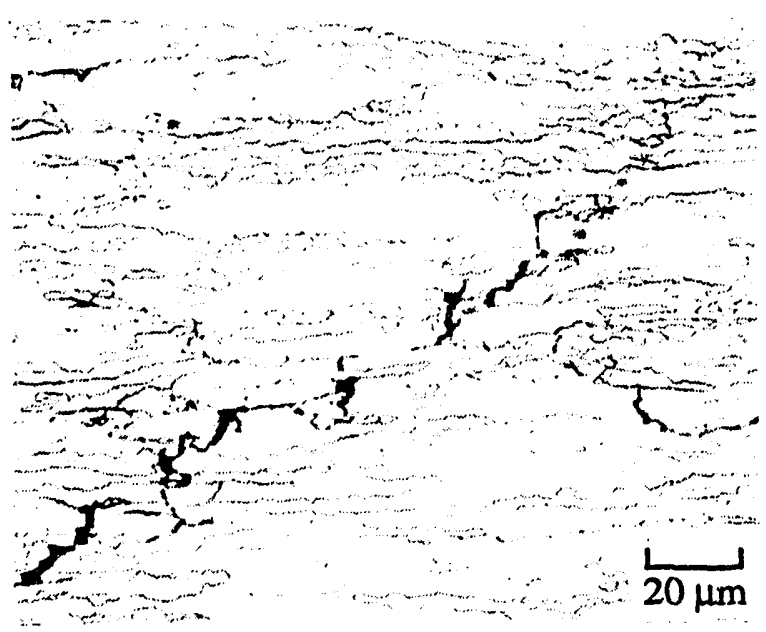

Figure 2-a. Optical light micrograph of a section of a recovered fragment of tungsten which was shocked at $22^{\circ} \mathrm{C}$. Extensive amounts of cracking occurred as a result of the shock loading. There are no indications of plastic deformation, i.e. deformation banding, due to the shock loading. This suggests that the shock induced deformation was accomodated by fracture processes.

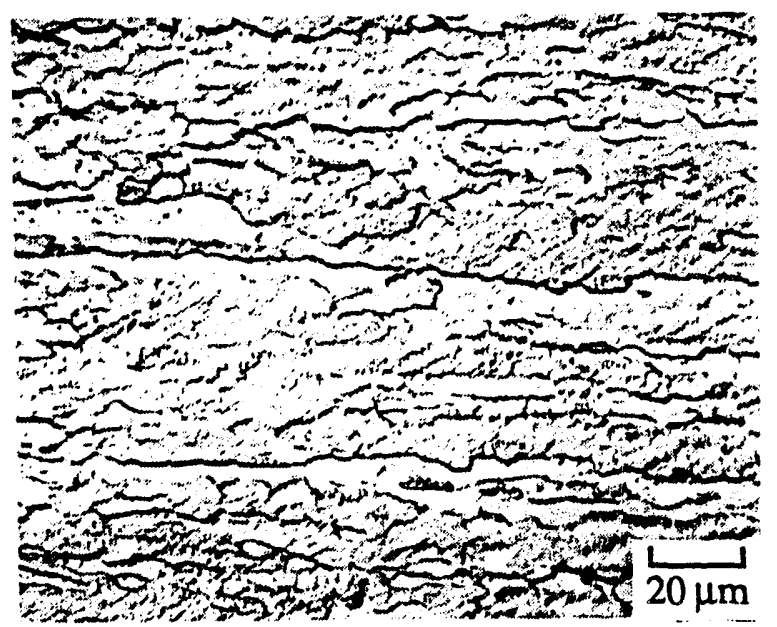

Figure 2-b. Optical light micrograph of the test material after shock loading at $400^{\circ} \mathrm{C}$. Banding of deformation is indicated diagonally across the microstructure. This banding is not observed in the test material in the starting condition, leading to the conclusion that the deformation banding is due to plastic deformation which occurred during shock loading. 
These TEM observations clearly indicate that the strains introduced into the test material during shock loading at $400^{\circ} \mathrm{C}$ were accommodated by dislocation generation and movement.

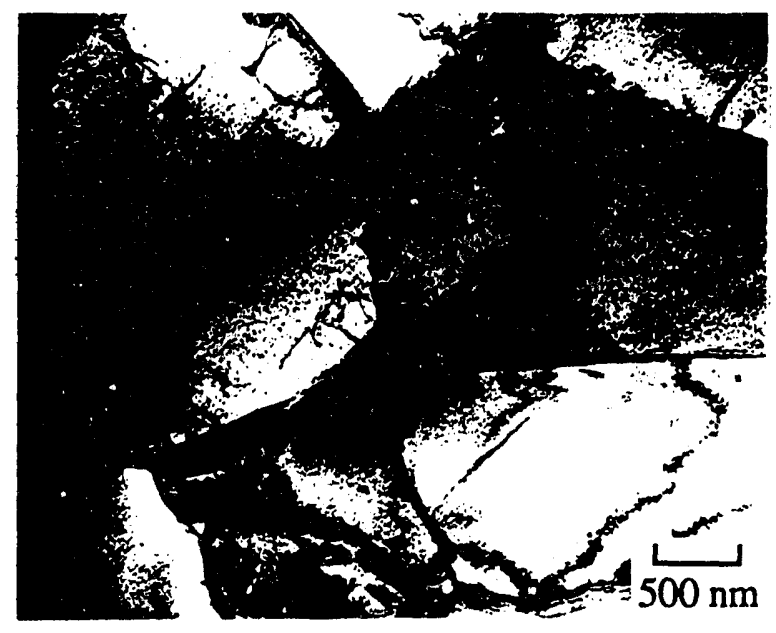

Figure 3-a. TEM micrograph of the test material in the as-warm-forged condition. Note the extensive network of low angle grain boundaries which form subgrains on the order of $3 \mu \mathrm{m}$.

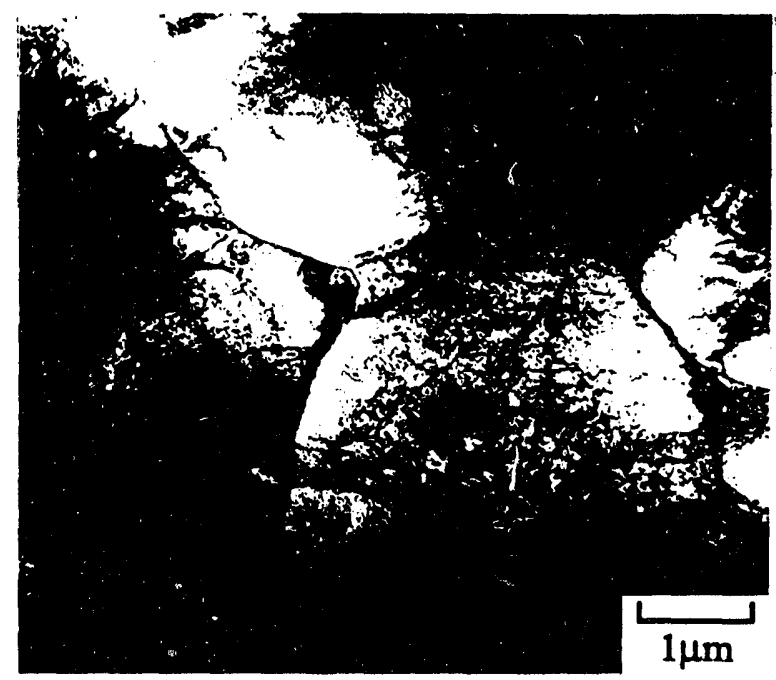

Figure 3-b. TEM micrograph of the material shock loaded at $4 \mathrm{CO}^{\circ} \mathrm{C}$. The shock loading produced a substantial increase in the dislocation density. There are some indications of dislucation substructure with cell sizes on the order of $300 \mathrm{~nm}$ in diameter.

\subsection{Scanning Electron Microscopy}

Fracture surface features of the tungsten sample that was shocked at $22^{\circ} \mathrm{C}$ were examined using scanning electron microscopy (SEM). A distinct difference in the morphologies of the fractures was observed in the planes normal and parallel to the forging (and shock propagation) direction. Cracking that occurred in the plane normal to the forging direction, as shown in Figure 4-a, was found to be predominately intergranular in nature, with polygonal features corresponding to the size and shape of subgrains identified using TEM. Significant amounts of secondary intergranular cracks are also present on these surfaces. Cracking that occurred in planes parallel to the forging direction, as shown in Figure 4-b, was found to be of mixed character with relatively equal amounts of intergranular and transgranular features. It is clear from these SEM observations that the shock loading at $22^{\circ} \mathrm{C}$ caused massive amounts of internal damage with crack dimensions ranging from submicron to millimeters.

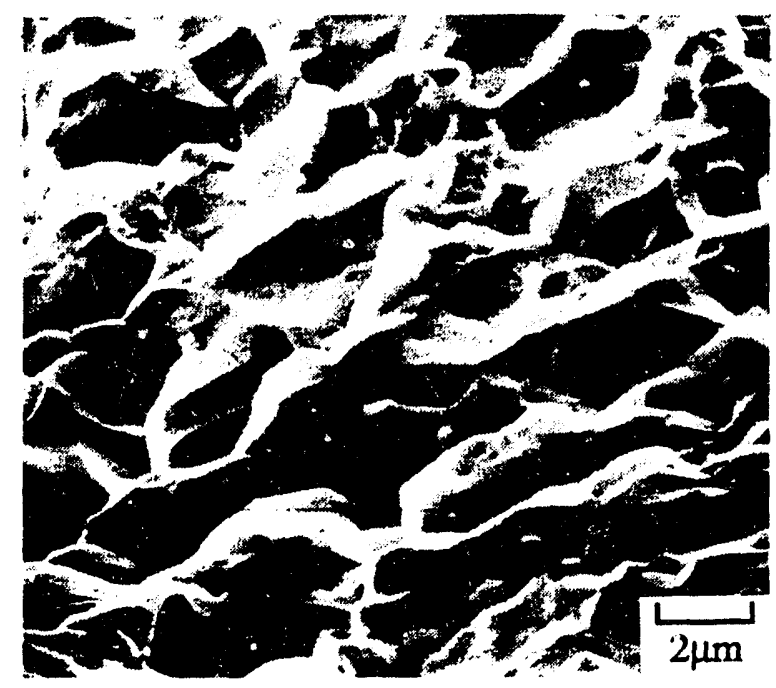

Figure 4-a. SEM micrograph of a fracture plane normal to the shock propagation. This fracture surface has polygonal features on the order of $3 \mu \mathrm{m}$ in diameter that are intergranular in nature.

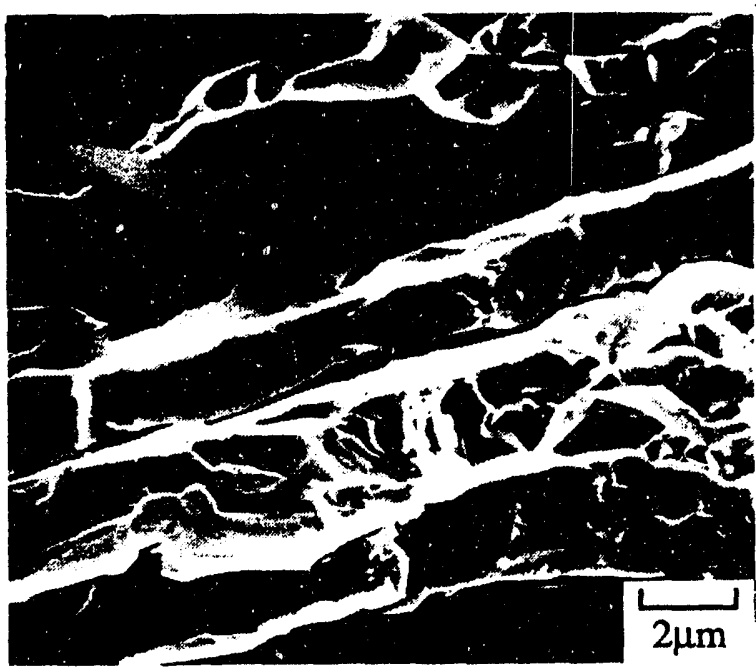

Figure 4-b. SEM micrograph showing the predominately transgranular fracture paths of cracks which propagated parallel to the propagation of the shock wave. 


\section{DUCTILE - BRITTLE TRANSITION BEHAVIOR UNDER SHOCK LOADING}

Planar shock waves impose a unique combination of uniax́ial-strain-deformation, temperature and pressure histories on solids, as shown schematically in Figure 5. The strain rates during the shock-rise and release are generally on the order of $10^{6}$ to $10^{7} \mathrm{~s}^{-1}$ and, in general, the temperature and pressure increase during the shock-rise and decrease during the release.

Increase in temperature during the shock-rise occurs due to conversion of mechanical work into thermal energy and because the material is adiabatically compressed (note that the former is a function of the constitutive behavior of the material and hence is affected by the microstructure, impurity levels, etc.). Decrease in temperature generally occurs upon shockrelease because adiabatic Jecompression generally results in a larger decrease in temperature than the continuing increase in temperature due to mechanical work. A shock pressure of $19 \mathrm{GPa}$ is estimated to result in a temperature increase of approximately $37^{\circ} \mathrm{C}$ and a residual temperature after shock release of $10^{\circ} \mathrm{C}$ (13). These changes in material temperature are relatively small and we may ignore them, i.e., we may assume our experiments are isothermal. However, higher shock pressures typically produced by high explosives produce temperatures rises on the order of hundreds of degrees Celsius and can not be ignored.

The amount of strain that occurs during the shock-rise and release is primarily a function of some of the physical properties of the solid and not strongly dependent on the microstructure or mechanical behavior of the material. Because of this, we can use established shock Hugoniot data for tungsten and the following expression to calculate the transient equivalent-strain, $\varepsilon_{s t}$, produced by the shock loading (shock-rise and release),

$$
\varepsilon_{s t}=\frac{4}{3} \ln \left(\frac{V_{s}}{V_{o}}\right)
$$

where Vo is the initial specific volume and Vs is the specific volume at the peak shock pressure determined from the Hugoniot for tungsten. The transient shock strains calculated for the experiments performed in this work are given in Table 1.
Metals can accommodate imposed strain fields by any of several well documented mechanisms depending on the deformation conditions (temperature, pressure, strain-rate, etc.). In the case of tungsten under the conditions of shock loading, shock induced strain is first accommodated by elastic deformation. Further straining can be accommodated by dislocation generation and movement, and/or deformation twinning, and/or a microcracking related mechanism. Note that microcracking during shock loading would have to be associated with shear loading (Mode II and/or Mode III cracking) because of the absence of tensile stresses during shock-rise and release. It may be argued that the deformation mechanism(s) which accommodated the imposed strain will be essentially the one(s) which contribute the least to increase in internal energy.

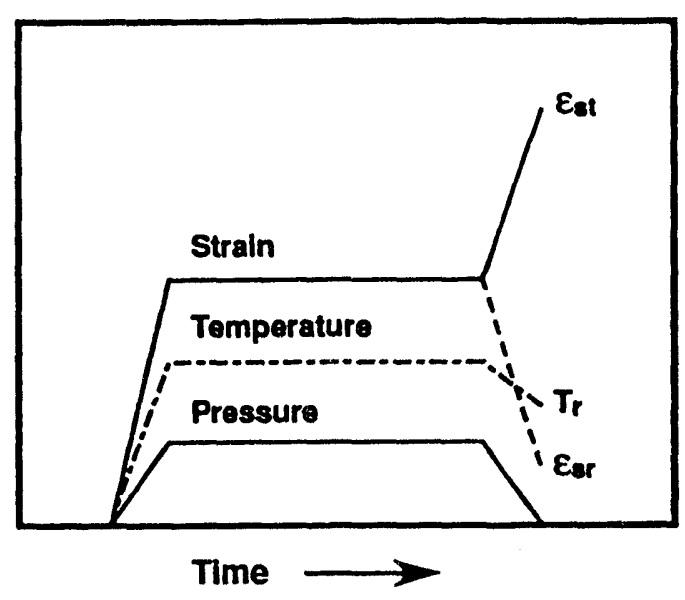

Figure 5. Schematic of the strain, temperature and pressure histories associated with shock loading. The state of strain is uniaxial (all components of the strain tensor are zero except the strain parallel to the shock propagation direction.) Transient strain, residual strain and residual temperature $\left(\varepsilon_{\mathrm{st}}, \varepsilon_{\mathrm{Sr}}\right.$ and $\mathrm{Tr}$, respectively) are, to a large extent, a function of the constitutive response of the test material.

The process of determining (and quantifying) a ductile-brittle transition behavior under uniaxialstrain shock loading is difficult because of the complex deformation history associated with planar shock as described above. The work presented here provides some insight into the topic of DBT behavior under the unique deformation conditions associated with shock loading. If the microcracking of the test sample shocked to $19 \mathrm{GPa}$ at $22^{\circ} \mathrm{C}$ occurred during the 
shock-rise, which appears to be the case, then we can conclude that shock loading at pressures greater than $19 \mathrm{GPa}$ will also result in microcracking of the test material. If the microcracking occurred during shock release we can not make this statement because of the significant effects of temperature and pressure on the mechanical behavior of tungsten. For example, the higher temperatures associated with higher shock pressures would favor a dislocation deformation mechanism resulting in an effective decrease in the DBTT relative to the initial test temperature. Although we note that the higher strain-rates associated with higher shock pressures would favor brittle behavior.

Because of the very complex nature of the DBT under shock loading, better understanding will most likely come from the computer code simulations of the experiment using physically based models for damage and an accurate constitutive model for strength.

\section{SUMMARY}

Shock/soft-recovery experiments on warm forged tungsten have been performed at $22^{\circ} \mathrm{C}$ and $400^{\circ} \mathrm{C}$. The major findings of this work are as follows:

1. Based on microstructural analyses, at $22^{\circ} \mathrm{C}$ the shock (19 GPa)-induced strains appear to be accommodated by fracture processes, i.e. indications of shock induced plastic deformation were not observed. The shock-induced damage (internal cracks) resulted in the reduction of the test sample to rubble.

2. A sample of material shock-loaded at $400^{\circ} \mathrm{C}$ was successfully recovered intact. Microstructural analyses indicated that the shockinduced plasticity caused deformation banding and an increase in the dislocation density of the material.

3. The results of these experiments demonstrate the principle of a ductile-brittle transition behavior under uniaxial shock loading conditions. Based on microstructural analyses it is hypothesized that shock loading at $22^{\circ} \mathrm{C}$ to pressures greater than or equal to $19 \mathrm{GPa}$ will result in extensive microcracking of the forged tungsten used in this study.

\section{ACKNOWLEDGMENTS}

The authors would like to gratefully acknowledge the contributions of the following individuals: Mr. Carl Trujillo (shock experiments), Mr. Robert Kershaw (metallography), Ms. Mary LeBlanc (mechanical testing), and Mr. James Yoshiyama (SEM examinations). This work was performed under the auspices of the U.S. Department of Energy by the Lawrence Livermore National Laboratory under Contract No. W-7405- Eng-48.

\section{REFERENCES}

1. J. H. Bechtold and P. G. Shewmon, Trans. Am. Soc. Metals 46 (1954) 397.

2. J. W. Clark, "Flow and Fracture of Tungsten and its Alloys: Wrought, Recrystallized, and Welded Conditions," (Air Force Systems Command, Technical Documentary Report No. ASD-TDR-63-420, April 1963).

3. P. L. Raffo, J. Less-Common Metals 17 (1969) 133.

4. G. T. Hahn, A. Gilbert and R. I. Jaffee, "Refractory Metals and Alloys II, Metallurgy Society Conference" Vol. 17 (Interscience, New York, London, 1962).

5. J. R. Stephens, "Effects of Interstitial Impurities on the Low-Temperature Tensile Properties of Tungsten" (Report NASATND 2287, 1964).

6. K. Farrell, A. C. Schaffhauser and J. L. Stiegler, J. Less-Common Metals 13 (1967) 141.

7. R. C. Koo, Trans Met. Soc. AIME 227 (1963) 280.

8. V. I. Trefilov and Yu. V. Milman, i2th International Plansee Seminar '89. Vol. 1. Refractory Metals and Related Topics, Superconductors, Reutte, Tirol, Austria, May 1989, (Metallwerk Plansee Gmbh, Reutte, Tirol, Austria, 1989).

9. A. Bussiba et al., Israel J. of Technology 24 (Proc. 4th Israel Materials Engineering conference) (1988) 703.

10. A. C. Chilton and A. S. Wronski, J. LessCommon Metals 17 (1969) 447.

11. D. H. Lassila and M. M. LeBlanc, "Deformation and Fracture Behavior of Tungsten-5\% R.ienium and Unalloyed Tungsten Under Dynamic Tensile Loading," High Strain Rate Behavior of Refractory Metals and Alloys, Cincinnati October 1991 (TMS ,1992), pp. 157-165.

12. J. C. Huang and G. T. Gray III, Mat. Sci. and Eng. A103 (1988) 241.

13. M. A. Meyers and L. E. Murr (eds.), "Shock Waves and High-Strain-Rate Phenomena in Metals," Plenum Press, New York, 1981, Appendix B. 

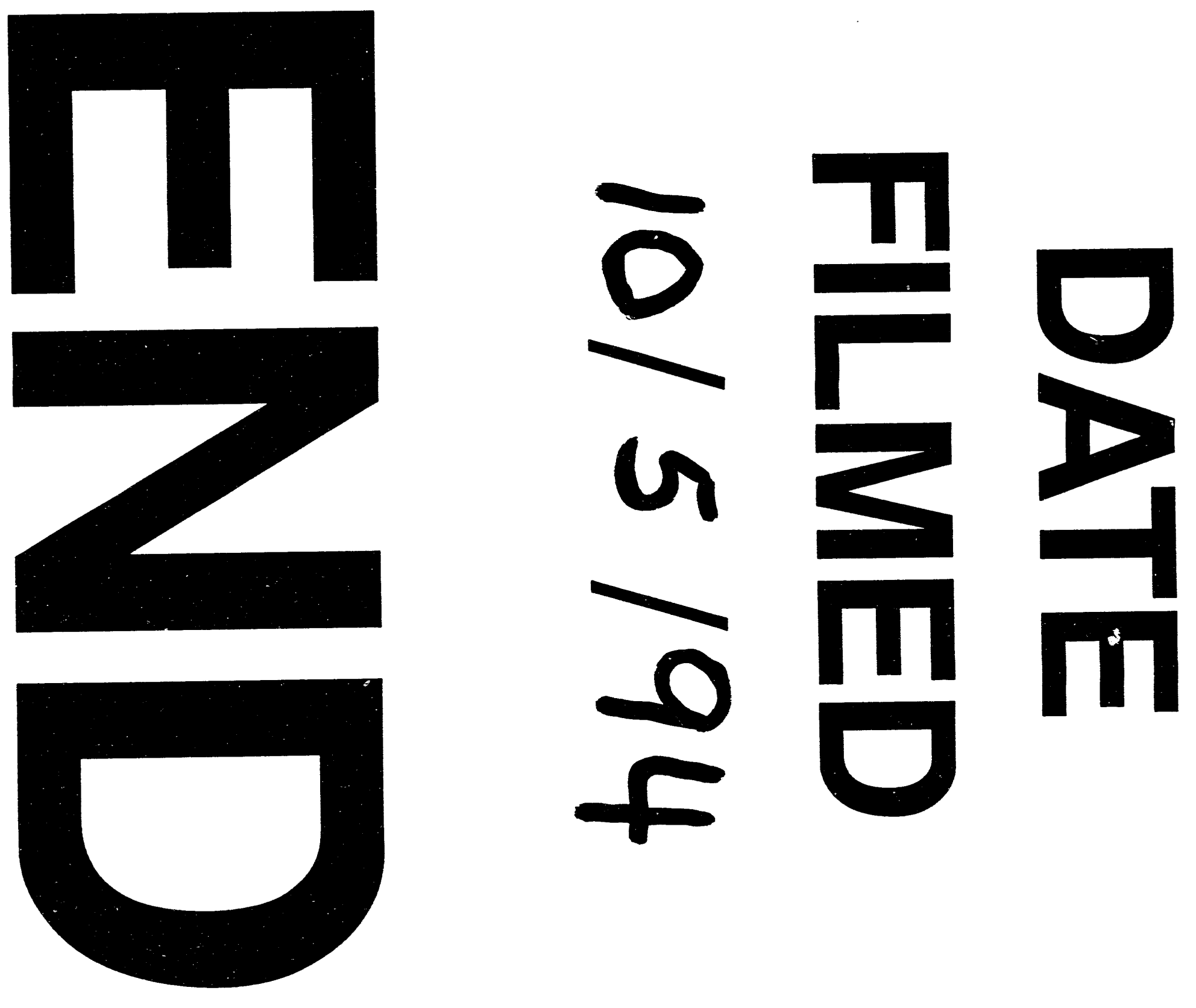
